\title{
Google Classroom: An online learning environment to support blended learning
}

Kizzy Beaumont

Keele University

\begin{abstract}
Google Classroom is a free web service, providing a collaborative tool allowing users to create virtual classrooms, where by they can post assignments, organise folders, and view documents in real time. Google Classroom was initially adopted by the Student Learning Department at Keele University to create a blended approach to university-wide freestanding academic skills development workshops, providing an online community for students to share and open dialogue around topics discussed during workshops. The aim was to bring students from different faculties together and create a sense of community surrounding enhancement of academic practice. Google Classroom provides an intuitive and accessible interface for both staff and students. From both a student and staff perspective at Keele, feedback was very positive. Students engaged in discussions, answered and posed questions to encourage discussion, and gave feedback on resources. This article will demonstrate how the Student Learning Department at Keele University has used Google Classroom and shared user guidance for colleagues to explore in their own practice.
\end{abstract}

\section{Keywords: Google Classroom, VLE, virtual classroom, blended learning}

\section{Introduction to the technology}

Since its launch in May of 2014, Google Classroom has been predominantly used by teachers and students situated within schools. However, a growing number of higher education institutions are taking to the platform. Google Classroom is part of the G Suite (Google Apps for Education) platform of cloud based computing apps, acting as a single dashboard to unify educator's use of other Google apps. Google's main aim for the virtual classroom app is "...to connect the class easily, track student progress and achieve more together" (Google for Education, 2018).

The functionality of Google Classroom has developed since its launch in 2014 and Google continues to update and review the platform to meet the requirements of its users. Recent updates include: live annotation of pdfs, importing of Google Forms quiz grades, creation of individualised posts. This article aims to demonstrate, with the use of a case study, how Google Classroom can be used within Higher Education and review its functionality and ability to engage students with educational content and practice.

\section{Application of the technology}

The Student Learning department at Keele University runs a series of university-wide freestanding workshops focusing on developing students' academic practice. In 2017/18, Google Classroom was used to create a blended approach, providing an online community 
for students to share and open dialogue around topics discussed during workshops and view, use and review resources. The aim was to bring students from different faculties together and create a sense of community surrounding enhancement of academic practice.

In the advent of the blended learning movement, educators are being encouraged to adapt their teaching to expand beyond the physical classroom. With regards to the concept of blended learning, there is no clear definition however simply put, it combines online digital media with traditional classroom methods (Thomlinson \& Whittaker, 2013), and has been established to be more effective than individual aspects of teaching methodology (Garrison \& Vaughan, 2008; Means et al., 2009). In addition, blended learning has shown to increase student motivation \& engagement with the subject matter (Garrison \& Vaughan, 2008; Gray \& DiLoreto, 2016). Not only do online classrooms support the blended-learning approach, but they can also be used to create a sense of community around learning and a positive relationship between a sense of community and an individual's ability to function within it has been documented (Garrison \& Vaughan, 2008; Glynn, 1981; Harrison \& West, 2014; Rovai \& Jordan, 2004). To support this notion of blended learning and its benefits, a wide variety of online tools and platforms have become available to educators over the last decade.

In previous iterations of the Student Learning workshops Blackboard, Virtual Learning Environment (VLE), and emails were used to communicate and share resources with students outside the classroom. However, both methods encouraged very little student engagement and were merely used for tutors to share resources. The Student Learning Department selected Google Classroom for its intuitive and accessible interface for both staff and students, and the possibility to create an online community through the chat functions. This allowed for a less formal space for staff and students to converse, bridging the gap between the formal, institutionally bound, VLE space and the variety of informal social media platforms. In addition, the possibilities for collaborative work between students (and staff) offered by Google apps which can be shared via Google Classroom, is a unique selling point and supports development of real-world digital skills.

\section{A review}

Within Google Classroom, virtual classroom spaces can be created with ease, and anyone with a Google account can both set up and join Google Classrooms. Student enrolment is simple and can be done in one of two ways; through manual enrolment using email accounts or by self-enrolment using a code generated for the specific classroom. In relation to this case study, the self-enrolment option was preferred as students are able to choose whether they wish to engage further with the resources and discussion or just attend the face-to-face workshops. With regards to the new General Data Protection Regulation (GDPR) policy reform, G Suite, the dashboard through which educators access Google Classroom, is GDPR compliant and the Department's use of the platform is in accordance with University policy. 


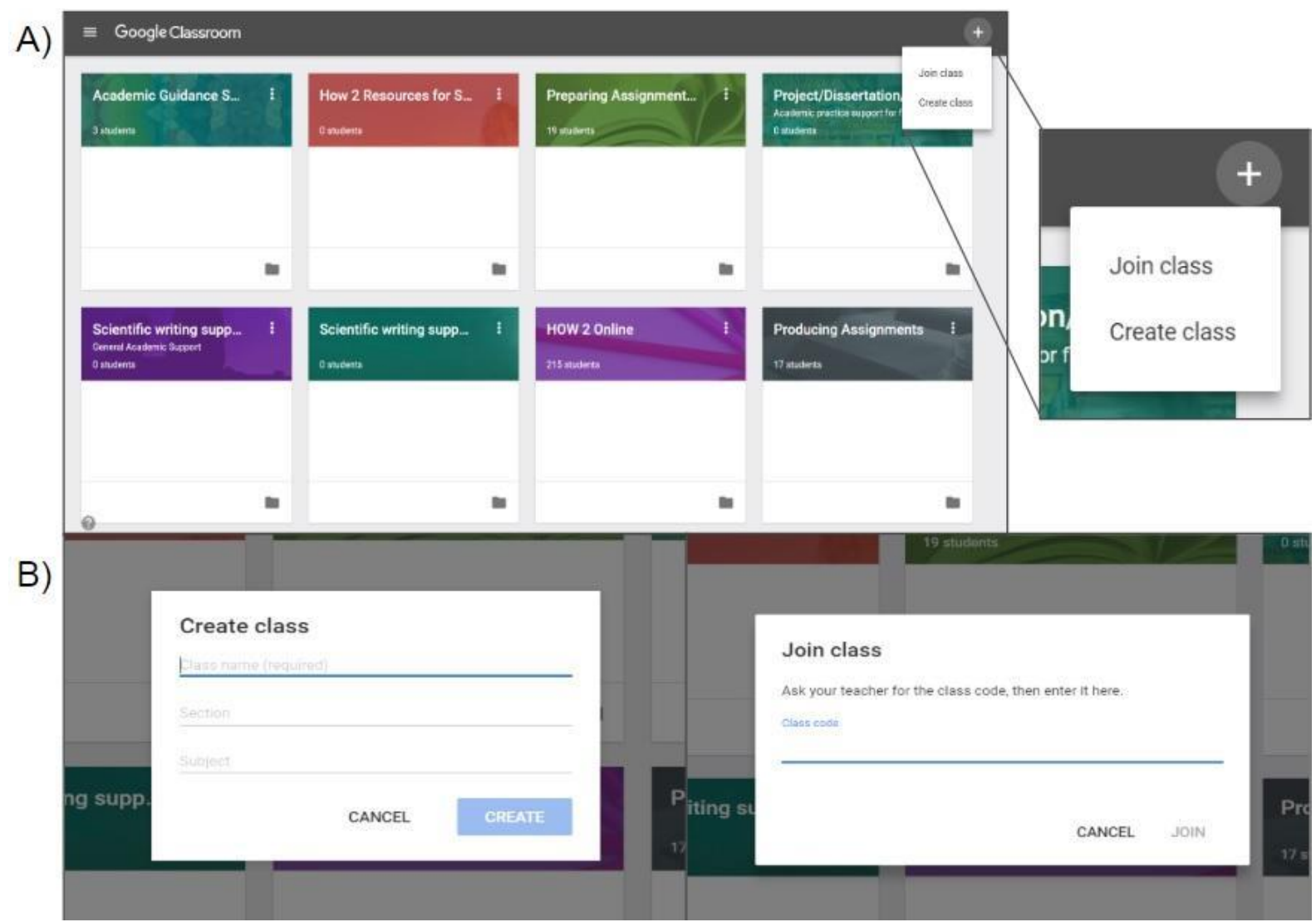

Figure 1: A) Example of Google Classroom homepage B) example of creating/joining classroom interfaces.

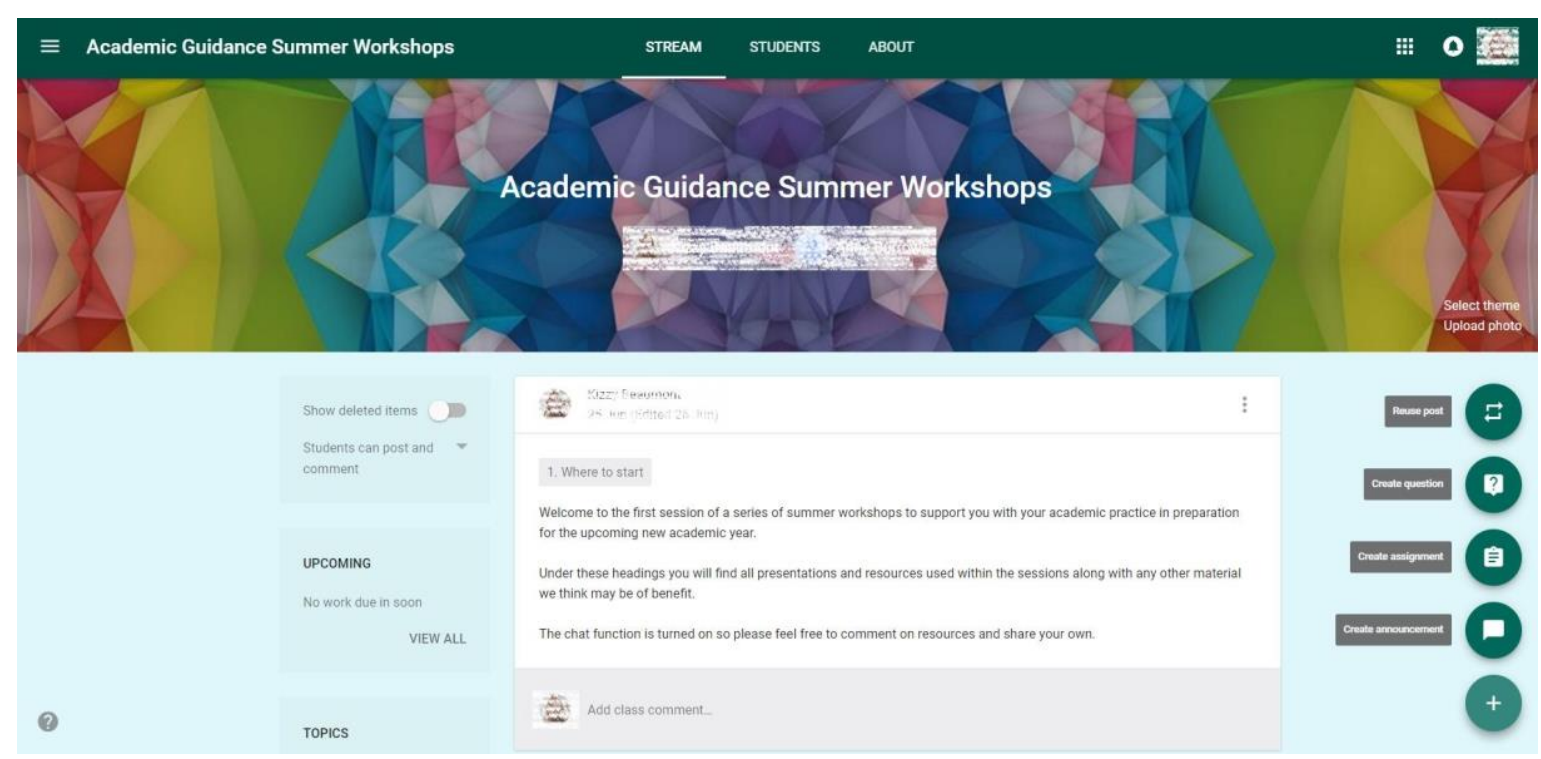

Figure 2: Example of a Google Classroom interface.

From both a student and staff perspective, feedback on Google Classroom was very positive. Students engaged in discussions and answered and posed questions to encourage discussion. The most effective aspect of student engagement with the platform was their ability to give feedback on resources. After weekly workshops, both resources used within 
the workshop and additional supportive material were placed on the Google Classroom. Students were encouraged to comment on any resources they found particularly useful or even ones they did not. In the later instance, students were also encouraged to share other resources they found more useful hopefully giving them a sense of collaboration.

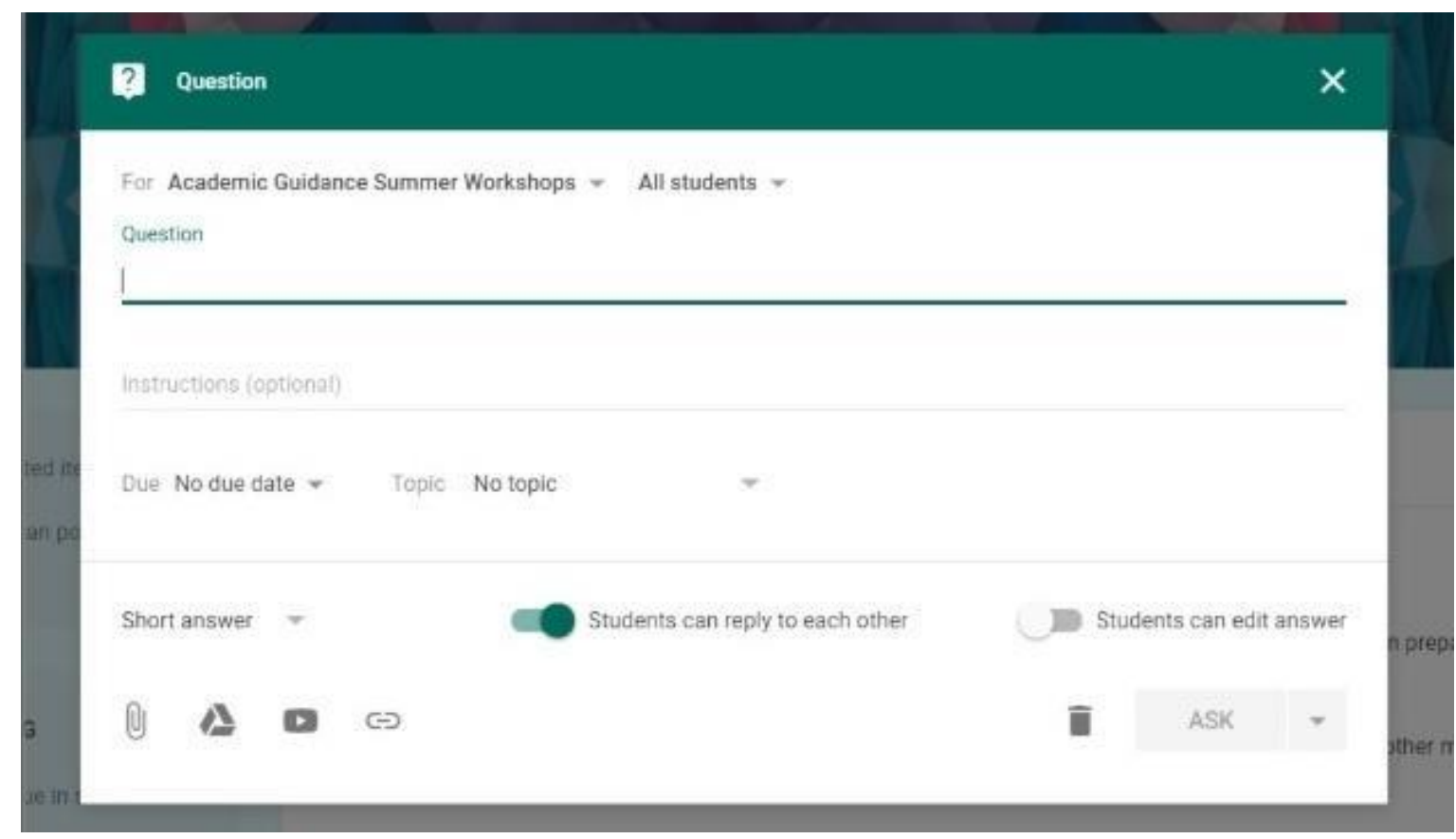

Figure 3: Example of adding a 'Questions' interface.

From an educators perspective Google Classroom could not be any easier to use, especially if you are already a Google applications user. Google Classrooms are easy to create and, more specifically, easy to enrol individuals or groups of students. One particular aspect which staff considered a true benefit is the scheduling of posts (see figure 2 above). Posts (whether it be; questions, announcements, assessments etc.) can be scheduled so they can be created ahead of time and are released at dates and times set by the creator. This works particularly well when wanting to release resources during sessions and follow-up questions throughout the week. Additional positives of the platform include: the ability to undertake collaborative work and the use of the assessment function. If you wish your students to undertake any form of collaborative work, the many Google apps (Docs, Sheets, Slides, Sites, and Calendar etc.) can be shared and worked on simultaneously via the Classroom. When releasing resources through the assessment function, Google Classroom will create a copy of the resource for each student allowing them to download and edit. If you do just wish the space to be used as a repository for resources then the chat function can be disabled. Google Classroom does have its imperfections however, they do not affect dramatically on the usability of the platform and once you are aware of the limitations you can work around them with reasonable ease. 
Table 1: Summary of Student Learning staff review of Google Classroom functionality.

\begin{tabular}{|l|l|}
\hline \multicolumn{1}{|c|}{ Positives } & \\
\hline Mobile friendly & Unable to format text \\
\hline Easy to create \& navigate & Unable to embed images, videos etc. \\
\hline Free Android and Apple app & Automatic arrangement of posts \\
\hline Integration with other Google apps & $\begin{array}{l}\text { Unable to hide or re-schedule posts once } \\
\text { posted }\end{array}$ \\
\hline $\begin{array}{l}\text { Collaborative work opportunities on Google } \\
\text { documents/slides/sheets/calendar/sites }\end{array}$ & Difficult to access learner analytics \\
\hline Allows for open Q\&A & \\
\hline Turn chat function on and off & \\
\hline Re-use posts across classrooms & \\
\hline Can schedule posts ahead of time & \\
\hline
\end{tabular}

\section{Conclusion}

Google Classroom is an effective platform for educators to use for a variety of educational purposes and can increase student engagement with ad hoc sessions using follow up $Q \& A$, tasks and discussion topics. Google Classroom is versatile (blended learning, flipped classroom and exclusively online classrooms), easy to use from both a staff and student perspective and allows for collaborative work to be undertaken with ease. If you are aware of Google Classrooms current limitations then you can work around them without causing too much impact on ease of use. The Student Learning Department now use Google Classroom to support all areas of their practice including but not limited to: university-wide standalone workshops, support for in-house student conferences, faculty based sessions, distancelearning support and open communication forums. There is still much to do and learn in establishing whether Google Classroom can be used effectively in creating a sense of community through the shared want to improve academic practice however, it is clear that the platform can be effectively used, with limited effort, to support student learning.

For more info on Google Classroom: https://edu.google.com/int//en uk/products/productivitytools/classroom 


\section{Technology Reviews}

\section{Reference list}

Boston, W. E., \& Ice, P. (2011). Assessing retention in online learning: An administrative perspective. Online Journal of Distance Learning Administration. Available at:

http://www.westga.edu/ distance/ojdla/summer142/boston ice142.html (Accessed: 24 April 2018).

Garrison, D. \& Vaughan, N. (2008). Blended learning in higher education: Framework, principles, and guidelines. San Francisco, CA: John Wiley \& Sons. ISBN: 978-0-787-987701.

Glynn, T.J. (1981). Psychological sense of community: Measurement and application. Human Relations, 34(9), pp.789-818. Available at: http://psycnet.apa.org/record/198204728-001 (Accessed: 24 April 2018).

Google for Education. (2018). Google Classroom. [ONLINE] Available at: https://edu.google.com/int//en uk/products/productivity-tools/classroom/ (Accessed: 24 April 2018).

Gray, J. A., \& DiLoreto, M. (2016). The effects of student engagement, student satisfaction, and perceived learning in online learning environments. International Journal of Educational Leadership Preparation, 11(1). Available at: https://eric.ed.gov/?id=EJ1103654 (Accessed: 22 October 2018).

Harrison, J.B. \& West, R.E. (2014). Sense of community in a blended technology integration course: A design-based research study. The International Review of Research in Open and Distributed Learning, 15(6). Available at:

http://www.irrodl.org/index.php/irrodl/article/view/1907/3187 (Accessed: 22 October 2018).

Means, B., Toyama, Y., Murphy, R., Bakia, M. \& Jones, K. (2009). Evaluation of evidence based practices in online learning: A meta-analysis and review of online learning studies.

Washington, DC: U.S. Department of Education. Available at: http://repository.alt.ac.uk/629/ (Accessed 22 October 2018)

Rovai, A.P. \& Jordan, H. (2004). Blended learning and sense of community: A comparative analysis with traditional and fully online graduate courses. The International Review of Research in Open and Distributed Learning, 5(2). Available at:

http://www.irrodl.org/index.php/irrodl/article/view/192/274 (Accessed: 22 October 2018)

Tomlinson, B. \& Whittaker, C. (2013). Blended Learning in English Language Teaching. London, UK: British Council. ISBN: 978-0-86355-706-4. 